\title{
Structural estimation of a principal-agent model: moral hazard in medical insurance
}

\author{
Marcos Vera-Hernández*
}

Despite the importance of principal-agent models in the development of modern economic theory, there are few estimations of these models. I recover the estimates of a principal-agent model and obtain an approximation to the optimal contract. The results show that out-of-pocket payments follow a concave profile with respect to costs of treatment. I estimate the welfare loss due to moral hazard, taking into account income effects. I also propose a new measure of moral hazard based on the conditional correlation between contractible and noncontractible variables.

\section{Introduction}

Contract theory has been extremely important in the development of modern economic theory during the last thirty years. However, the increasing sophistication of the theory has not gone hand-in-hand with empirical validation of the models, as Salanié (1997) points out. Chiappori and Salanié (2003) offer an up-to-date perspective on the literature that has tried to link econometrics and contract theory. Most of the existing works have used a reduced-form approach. ${ }^{1}$

This article's main contribution is to estimate the parameters of a principal-agent model with moral hazard. This allows me to use the principal-agent paradigm when solving for the optimal contract. This presents two main advantages. First, principal-agent models have developed in the last thirty years as a rigorous framework for studying the moral hazard concept. For my purposes, the optimal contract can be obtained directly from first principles, so I do not need to make further assumptions about the first-best level of utilization. Second, this approach requires the analyst to make a clear distinction between contractible and noncontractible variables. The relation between these variables provides important information for deriving the optimal contract.

\footnotetext{
*University College London and Institute for Fiscal Studies; marcos.vera@ifs.org.uk.
}

I would especially like to thank Jaap Abbring, Jerome Ada, Pedro Barros, Richard Blundell, James Cardon, Paul Contoyannis, Michael Creel, Gautam Gowrisankaran, Hugh Gravelle, Roberto Leon, Albert Ma, Matilde Machado, Ines Macho, Costas Meghir, Bernard Salanié, Steven Stern, and Anita Todd for discussions that improved the article. Comments from two anonymous referees and the Editor also improved the article. I also received useful comments from Orazio Attanasio, Jim Burgess, Pierre-Yves Geoffard, Jerry Hausman, Hide Ichimura, Andrew Jones, Fuen Morales, Pau Olivella, Frank Windmeijer, and participants in a number of conferences and seminars (a list is available at www.ifs.org.uk/staff/marcos_v.shtml). All remaining errors are my responsibility. I thank the Management Science Group of the Veterans Administration for sponsoring the 13th Annual Health Economics Conference at Carnegie Mellon. This research has been supported by a Marie Curie Fellowship of the European Community program, Improving Human Research Potential and the Socio-economic Knowledge Base, under contract no. HPMF-CT-2001-01206.

${ }^{1}$ See Chiappori (2000) for a review of empirical work in insurance under asymmetric information. Exceptions to the reduced-form approach are Ferrall and Shearer (1999), Margiotta and Miller (2000), Paarsch and Shearer (2000), Cardon and Hendel (2001), and Biais, Bisière, and Décamps (1999). 
I concentrate on the problem of health care insurance. Moral hazard in the use of medical services has been one of the most recurrent issues in health economics; early references on the topic are Arrow (1963), Pauly (1968), and Zeckhauser (1970). Moral hazard arises because health shocks are not contractible and consequently contracts are not complete. It might then be optimal for insurers to give incentives so the consumer will not seek expensive treatments for minor health shocks.

In the health care setting, it is natural to think that the noncontractible variable is the health shock, while the contractible variable is treatment cost. This will be important when deriving the optimal contract, since cost can indicate the severity of the health shock. This will also be the basis for our proposal of a new measure of moral hazard: the correlation between health shocks and treatment costs.

Previous articles have tried to estimate optimal health care insurance contracts (Feldstein, 1973; Feldman and Dowd, 1991; Buchanan et al., 1991; Newhouse et al., 1993; Manning and Marquis, 1996). However, their methodology is based on optimal taxation rather than asymmetric information theory. ${ }^{2}$ Medical insurance may distort the consumption of health care services, since it lowers the marginal price of consumption. In this respect, the problem of optimal taxation is similar to optimal health insurance. As Besley (1988) points out, however, there is a crucial difference between them: the insurance problem is against a background of incomplete markets. The previous approaches are based on comparing the welfare loss of a given insurance contract to the situation of no insurance. Consequently, they assume that the first-best level of health care services corresponds to the one where there is no insurance. Ma and Riordan (1997, 2002) have shown that this assumption does not hold true in the presence of income effects. In fact, the implementation of the first best requires the consumer to be responsible for only a fraction of treatment costs, because the marginal valuation of income rises once the consumer pays her out-of-pocket portion. ${ }^{3,4}$ In this article I can deal with this issue because I obtain the optimal contract directly from first principles as the solution to the principal-agent problem. ${ }^{5}$

This article also differs from previous literature in the way I model health care consumption. In previous approaches, the individual decision is over the amount of monetary resources dedicated to health care. Hence, utility would be a function of the amount of dollars spent in an illness episode. Though this is a simplifying assumption, it is undesirable because it assumes that the larger the health care costs, the higher the utility. It is preferable to disentangle quantity consumed from the cost of producing it, since the individual will derive utility from quantity but not from the cost of production. In my model, the individual decides whether or not to have treatment against an illness spell with some level of severity. The costs of treatment are given to the individual as a technological relation. My approach, though more complicated from an econometric point of view, allows me to disentangle quantity from costs. An important advantage of this approach is that I can exploit the stochastic relation between costs and health shocks when solving for the optimal contract. If treatment costs are strongly correlated with health shocks, then the problem of moral hazard will be alleviated because the insurer can infer the value of the noncontractible variables from the contractible ones. ${ }^{6}$ This informational relation will be my basis for proposing

\footnotetext{
${ }^{2}$ The term moral hazard originated in the insurance context, but it has evolved and expanded. Nowadays it is natural to draw on the developments of the incomplete-contracts literature when discussing moral hazard in the insurance context (Winter, 2000).

${ }^{3}$ Ellis and McGuire (1993) are also reluctant to identify the first-best health care utilization as the one obtained without insurance. This is related to an early observation by De Meza (1983) that previous approaches might overestimate welfare losses due to moral hazard in the presence of income effects. Cutler (2002) also emphasizes that moral hazard is the substitution effect, not the income effect.

${ }^{4}$ An interesting discussion on the role of income effects and related issues has been carried out in a recent volume of the Journal of Health Economics by Blomqvist (2001a, 2001b), Manning and Marquis (2001), and Nyman (2001). In contrast to them, I use the principal-agent paradigm.

${ }^{5}$ Blomqvist (1997) also obtains the optimal contract from first principles, but my model differs from his in a number of dimensions.

${ }^{6}$ Buchanan et al. (1991) also disentangle quantity consumed and health care costs, but they ignore the correlation between contractible and noncontractible variables and do not obtain the optimal insurance plan using the principal-agent paradigm. 
a new measure of moral hazard using the correlation between health shocks and treatment costs. This measure is based on the informational content that contractible variables (treatment costs) have over noncontractible ones (health shocks). The previous literature has used elasticities of health expenditures with respect to copayments as a measure of moral hazard. ${ }^{7}$ I view my measure of moral hazard as a complement rather than a substitute to the traditional elasticity measure. My measure checks for the support condition that is commonly assumed in theoretical models but has not previously been examined in empirical research. ${ }^{8}$ My measure is especially valuable if nonlinear contracts are allowed, as is commonly the case in health insurance contracts. See Cutler (2002) and Cutler and Zeckhauser (2000) for examples of nonlinear health insurance contracts in the United States.

I use data from the RAND Health Insurance Experiment (HIE) that randomly assigned individuals to insurance contracts. This is a significant advantage: in particular, I do not need to model the individual's choice of insurance contracts. Moreover, the randomization will also be important for the identification of the model.

The article is organized as follows. Section 2 describes the theoretical model and some of its implications. Section 3 describes the data. Section 4 discusses the econometric strategy used to estimate the theoretical model. Section 5 gives the results of a descriptive analysis. Section 6 discusses the estimates of the structural parameters and evaluates the suitability of the model. Section 7 sets up and solves the principal-agent problems and discusses my measure of moral hazard. Section 8 concludes. Finally, the Appendix contains details of the computation of the log-likelihood function.

\section{The demand model}

- Individual decision problem. This section is devoted to modelling individual decisions about whether or not to be treated when suffering an illness spell. This is the basis for the estimation of the parameters of the principal-agent model. In my setup, the consumer faces a specific insurance contract that will influence her decision.

My model draws on Ma and Riordan $(1997,2002)$. Their model is well suited for my purpose, as they consider income effects and separate quantity from treatment costs. The main difference between their model and mine is that I allow treatment costs to be random and stochastically related to illness severity (health penalty). From an empirical point of view, this is important for obtaining my measure of moral hazard. ${ }^{\text {? }}$

In the model, the individual decides whether or not to be treated but does not decide the cost of treatment. In fact, Keeler and Rolph (1988) and Newhouse et al. (1993) found that insurance contracts mainly influence the decision whether or not to seek treatment against an illness episode, rather than the treatment costs. This is expected given the informational asymmetry between doctor and patient. I shall also assume that the doctor chooses treatment costs independently of the individual's insurance contract and income. This corresponds to the situation where the medical guideline that the doctor follows does not take into account individual economic characteristics but gives the most cost-effective treatment. Consequently, I shall assume that treatment costs come from a given technological relation. I emphasize one important hypothesis in my model: The individual is rational and compares benefits and costs when she decides whether or not to seek treatment. This might be a strong assumption when one is dealing with severe illnesses for which the individual lacks experience and can hardly value the benefits and costs. Furthermore,

\footnotetext{
${ }^{7}$ Cutler and Zeckhauser (2000) review about 22 studies that estimate the elasticity of medical care.
}

${ }^{8}$ By support condition I mean that there is no deterministic function linking contractible and noncontractible variables. If there were such a function, the moral hazard problem would disappear (see, for instance, Winter (2000)). More generally, the correlation between contractible and noncontractible variables is likely to play a role when designing the optimal contract.

${ }^{9}$ This also allows me to obtain an empirical model that is not specific to an illness. There are some other differences between their model and mine. In my model, the illness probability and the health penalty shock are drawn from the same distribution, while in their model these processes are modelled independently. I need this assumption to be able to identify the parameters in the estimation. 
the treatment decision in the case of very severe illnesses might depend on long-term effects that would severely complicate the model. In the empirical application I shall restrict the type of illness spells studied to make behavior more likely to conform to modelling assumptions.

I assume the individual is endowed with a health capital stock $\bar{s}$ and an income level $y$. An individual is ill when she receives a penalty health shock of magnitude $s>0$. There is a stochastic relation between $s$ and $\bar{s}$, given by the density function $f_{s \mid \bar{s}}$. If $s \leq 0$, the individual is not ill and therefore treatment is not demanded. The support of $s$ is $(-\infty,+\infty)$.

The individual is under the coverage of an insurance contract that under premium $p$ reimburses the cost of the treatment $c$, if the individual agrees to pay the quantity $k * c$, where $k \in[0,1]$ is the copayment rate. The health penalty shock and cost of treatment variables will follow a joint density function that depends on both the health stock, $\bar{s}$, and cost shifters $\bar{c}$ given by

$$
g_{s, c \mid \bar{s}, \bar{c}}= \begin{cases}0 & \text { if } c<0 \\ 0 & \text { if } s \leq 0 \text { and } c>0 \\ f_{s \mid \bar{s}} & \text { if } s \leq 0 \text { and } c=0 \\ f_{s, c \mid \bar{s}, \bar{c}} & \text { if } s>0 \text { and } c>0 .\end{cases}
$$

The first line implies that costs cannot be negative, while the second one means that costs cannot be positive when the individual is not ill $(s \leq 0)$, since there is no need for treatment.

The timing of the model is as follows. First the individual receives a random draw of $(s, c)$ from the joint density $g_{s, c \mid \bar{s}, \bar{c}}$. When the individual suffers an illness spell $(s>0)$, she will obtain different utilities depending on her decision about treatment. I assume that the individual knows the health penalty $s$ and the cost $c$ when she decides. I also assume that in case the treatment is obtained, there is perfect healing and the initial level of health is fully recovered. Specifically, the consumer's ex post utility will be

$$
\begin{cases}U(y-p, s), & \text { if ill with health penalty } s \text { but treatment is not obtained, } \\ U(y-p-k * c, 0), & \text { if ill and treatment is obtained with } k * c \text { as out-of-pocket payment } \\ U(y-p, 0), & \text { if consumer is not ill. }\end{cases}
$$

I assume that $U(\cdot, \cdot)$ is increasing and concave in the first argument, while decreasing and convex in the second.

In what follows, I describe the individual decision problem. Given that the set of actions is discrete (to have or not to have treatment), it is of interest to look for the health penalty threshold that, given a cost, leaves the individual indifferent between having treatment or not. Below is the formal definition of the health penalty threshold.

Definition 1. The health penalty threshold is the function $\tilde{s}(c)$ such that $U(y-p, \tilde{s}(c))=$ $U(y-p-k * c, 0)$.

Given a draw of $(s, c)$ from the distribution implied by (1), the individual will decide to have treatment $(T=1)$ or not $(T=0)$, according to the following rule:

$$
T= \begin{cases}1 & \text { if } s>\tilde{s}(c) \\ 0 & \text { if } s \leq 0 \text { or } 0<s<\tilde{s}(c)\end{cases}
$$

The intuition is very simple. The individual will decide not to have treatment $(T=0)$ either when she is not ill $(s<0)$ or when the health penalty shock does not offset the out-of-pocket payment $(0<s<\tilde{s}(c))$. Notice that $\tilde{s}(c)$ depends on the copayment rate. In particular, if the copayment rate, $k$, is equal to zero, then the individual will decide to have treatment when she is ill, independent of the treatment costs. As expected, $\tilde{s}(c)$ is increasing in the copayment $k$. This means that the greater the copayment, the greater must be the health penalty in order to ask for treatment, given a cost. It is also the case that the expected cost, $E[c \mid k]$, is decreasing in the 
copayment rate. However, notice that

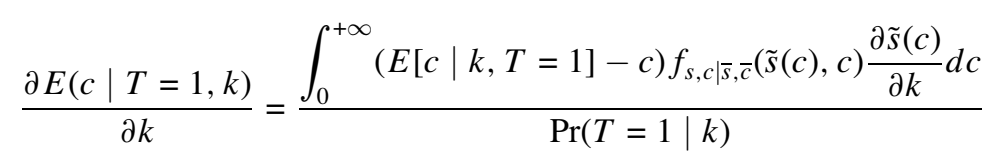

can be positive or negative, depending on parameter values. Consequently, it is ambiguous how the expected cost conditional on having a treatment changes with the copayment rate. Two opposing forces are at work here. On one hand, given a value of health penalty, consumers facing high copayment rates will have treatment only if the treatment is inexpensive enough. On the other hand, it might be the case that consumers facing high copayment rates will have treatment, on average, for relatively severe episodes. However, consumers facing zero copayment rates will also have treatment for relatively minor episodes. This last effect will increase the expected cost conditional on having treatment for consumers facing high copayment rates relative to those facing zero or low copayment rates.

\section{The data}

- The experiment. The data I use come from the RAND Health Insurance Experiment (HIE), a social experiment conducted between 1975 and 1982 at six different U.S. sites: Dayton, Ohio; Seattle, Washington; Fitchburg and Franklin County, Massachusetts; and Charleston and Georgetown County, South Carolina. Families participating in the experiment were randomly assigned to one of fourteen different fee-for-service health insurance plans. Eligible individuals for the experiment were younger than 61. More information about the experiment can be obtained in Manning et al. (1987) and Newhouse et al. (1993).

I would like to highlight two important characteristics of the dataset. First, insurance plans are exogenous to the individuals. Individuals did not choose their insurance plan, but were randomly assigned. Therefore, the analyst does not face the problem of endogenous insurance coverage, that is, the possibility that less-healthy people, anticipating large medical expenditures, buy more generous insurance coverage.

Second, it gives information on illness episodes. Claims from providers were grouped to create episodes of treatment. For each episode, the dataset contains information on total expenses, as well as the type of episode and the principal provider of the service. Episodes are classified as acute, chronic, chronic flare-up, ${ }^{10}$ well-care, and prenatal/maternity. The classification for providers includes hospital inpatient, hospital outpatient, physician, dentist, pharmacy, and nonpharmacy supplier. The classification of the provider is hierarchical, that is, outpatient services preceding or following a hospitalization were classified as a hospital provider. Drugs and tests were part of the episode in which they were prescribed. This information about the type of episodes will be useful when restricting the type of illness spells that I use. More information on how episodes were constructed can be obtained from Keeler and Rolph (1988) and the references therein.

The fee-for-service plans of the experiment had different levels of cost sharing that varied over two dimensions: the copayment rate (the percentage of the cost of each insurance claim that the individual paid out of pocket) and an upper limit on annual out-of-pocket expenditures called maximum dollar expenditure (MDE). Consequently, the family only paid according to the copayment if the total out-of-pocket expenditures had not exceeded the MDE. The copayment rates were $0 \%, 25 \%, 50 \%, 95 \%$, or $100 \%$. Depending on the plan, the MDE was $5 \%, 10 \%$, or $15 \%$ of the previous year's income, with a maximum of $\$ 4,253$ (2002 dollars). ${ }^{11}$ Below I comment on the consequences of this MDE. Participants in the experiment did not pay any insurance premium.

${ }^{10}$ A temporary problem in a usually controlled condition.

${ }^{11}$ Apart from the ones mentioned above, there was an HMO plan as well as an individual deductible plan that limited annual out-of-pocket outpatient expenditures to $\$ 637.90$ per person (2002 dollars), with a $95 \%$ copayment rate for outpatient expenditures. These will not be used in this study. 
$\square \quad$ The sample. In this subsection I specify the sample used in the estimation. I begin by discussing the types of episodes used. In my structural model, individuals can receive a health penalty shock. This is not compatible with treatments that can be predicted in advance, such as well-care, prenatal care, maternity care, or chronic care. I exclude episodes of care for such treatments. I further exclude inpatient episodes, since they are often quite severe and individuals are less likely to decide about such treatments on the basis of economic factors. ${ }^{12}$

Summarizing, I limit my sample to acute and chronic flare-up outpatient episodes. Acute episodes (Newhouse et al., 1993) are defined by unforeseen and undeferrable treatment opportunities. From an economic point of view, spending on these episodes will occur only when the patient is temporarily sick. Chronic flare-up episodes are similar to acute episodes but are caused by a chronic condition. Since I have not considered inpatient episodes, most of the episodes will result from relatively minor conditions. In addition, it is important to have a relatively homogeneous sample of illness episodes, since in general the consumption of different health care commodities will imply different optimal insurance contracts associated with them (Besley, 1988). For instance, it is a common empirical fact that cost-sharing levels of inpatient episodes are lower than outpatient ones.

Most individuals in the dataset were enrolled for three contract years (contracts had a duration of 365 days but they did not correspond to natural years, so they were called contract years), though a subsample was enrolled for five years. Enrollment duration was not an individual's decision but was part of the experimental design. I will use observations on all the available contract years for an individual, so my estimation dataset will be an unbalanced panel.

My model does not allow for multiple spells. As we will see, the econometric implementation needs to account for sample selection in costs because I do not observe the treatment costs of those who were ill but did not seek treatment. Consequently, the model is already quite complex without the added complication of accounting for multiple spells. Therefore, the dependent variable is a dichotomous variable that takes a value of one if the individual began treatment for a new episode during the first month of each contract year. ${ }^{13}$ We have 6,780 valid person-year observations. Only $1.56 \%$ of them had two episodes in a month, and .15\% had three episodes. Consequently, I think that the multiple-episode problem is not important in the data selected for analysis. As in Gilleskie (1998), if someone started more than one episode in the month, I use only the first one. Therefore, I have only one observation per person per contract year.

I only consider people older than 17 because I want to consider only episodes that are decided by the individual and not the parents. I also do not consider people who were self-employed (there were very few of these in the sample) because they might differ significantly in their opportunity costs of having a treatment, and I do not have information about this opportunity cost. Finally, I deleted observations with missing values in relevant variables. Table 1 gives the description of the variables used, as well as the descriptive statistics of the observations used in the estimation. The models were estimated using monetary variables valued in 1973 dollars (as entered in the data). In this article I show all the monetary variables in December 2002 dollars. Because substantive technological change and economic growth has occurred since the dates of the experiment, the comparability of monetary values should be treated carefully.

The maximum dollar expenditure and the copayment rate. In the estimation I will condition on the individual's copayment rate. Therefore, it is important that the copayment rate I condition on is the same one that the individual uses to decide on demand for treatment. As Keeler, Newhouse, and Phelps (1977), Ellis (1986), Keeler and Rolph (1988), and Newhouse et

${ }^{12}$ I also do not consider dental episodes, since they were not usually covered by insurance contracts in those years and consumers showed opportunistic behavior during the experiment. I do not analyze mental care episodes, since they have different determinants, and even with generous insurance coverage, relatively little was spent on outpatient mental health care at the time the experiment was conducted.

${ }^{13}$ More specifically, during the second day of the contract year and the following 30 days. Medical expenses in the new contract year that were generated by illness episodes that started in the preceding contract year were recorded as starting the first day of the new contract year. I want to exclude them, since they are not decisions taken in the current contract year.

(c) RAND 2003 . 
TABLE 1 Description of Variables

\begin{tabular}{|c|c|c|c|}
\hline Variable & Mean & $\begin{array}{l}\text { Standard } \\
\text { Deviation }\end{array}$ & Description \\
\hline \multicolumn{4}{|l|}{ Endogenous } \\
\hline Treatment & .14 & .35 & $\begin{array}{l}=1 \text { if treated by an episode that started } \\
\text { in the first month, } 0 \text { if the contrary }\end{array}$ \\
\hline Costs $^{\mathrm{a}}$ & $\$ 143.8$ & $\$ 237.6$ & episode treatment cost \\
\hline \multicolumn{4}{|l|}{ Exogenous } \\
\hline Copayment & .32 & .37 & copayment rate: $0, .25, .5, .95,1$ \\
\hline Income $^{\mathrm{a}}$ & $\$ 1990$ & $\$ 1718$ & monthly per-capita family income at enrollment \\
\hline Female & .56 & .49 & $=1$ if female \\
\hline Health $^{\mathrm{b}}$ & 70.22 & 14.60 & $\begin{array}{l}\text { general health index }[0,100] \text {; higher values } \\
\text { indicate better health }\end{array}$ \\
\hline Education $^{\mathrm{b}}$ & 12.09 & 2.97 & number of years of education \\
\hline Disease $^{b}$ & 12.16 & 8.80 & $\begin{array}{c}\text { index for number of diseases, }[0,58.6] \\
\text { higher values indicate more diseases }\end{array}$ \\
\hline Age & 38.72 & 11.71 & age in years \\
\hline Appointment $\mathrm{t}^{\mathrm{b}}$ & 44.26 & 28.91 & $\begin{array}{l}\text { satisfaction with length of wait for medical } \\
\text { appointments, }[0,100] \text {; higher values } \\
\text { indicate greater satisfaction }\end{array}$ \\
\hline Seattle & .23 & .42 & $=1$ if person lives in Seattle, 0 otherwise \\
\hline Franklin & .17 & .37 & $=1$ if person lives in Franklin County, 0 otherwise \\
\hline Charleston & .13 & .33 & $=1$ if person lives in Charleston, 0 otherwise \\
\hline Year78 & .22 & .41 & $=1$ if observation corresponds to 1978,0 otherwise \\
\hline Year80 & .11 & .32 & $=1$ if observation corresponds to 1980,0 otherwise \\
\hline
\end{tabular}

${ }^{\text {a }}$ Valued in 2002 dollars.

${ }^{\mathrm{b}}$ Standardized for estimation.

al. (1993) have noted, the existence of a cap on out-of-pocket payments may make the effective marginal price differ from the nominal price (the copayment rate I condition on). If individuals were able to anticipate exceeding the cap with some probability, then the effective marginal price would be smaller than the nominal one.

I have reasons to think that in my case this is a minor problem. First, according to Newhouse et al. (1993), p. 106, "Few participants [in the HIE experiment] proved able to anticipate exceeding the MDE, which allowed us to ignore this factor and to obtain a much more tractable estimation problem." In addition, they show that the size of the remaining MDE was important in the decision to initiate a hospital episode but not to initiate other types of episodes. Consistent with the same idea, Keeler and Rolph (1988) showed that people participating in the experiment adopted a mixture of myopic and inflexible behavior. That is, if expenditures did not exceed the MDE, then they responded to current copayments. Once out-of-pocket expenditures exceeded the MDE, people did not adapt to the zero price of medical care instantly but instead took some time to do so.

My analysis is based on the first month. Given the references above, families in the first month of the contract year should be far from either exceeding the MDE or anticipating exceeding the MDE. Moreover, I will not use the insurance plan with a deductible, as the MDE for this plan was smaller than for the copayment plans. Therefore, I feel confident conditioning on the current copayment rate.

\section{Econometric specification}

- Functional-form assumptions. In this subsection I give functional-form assumptions that are maintained throughout. I use the subscript $t$ to denote that the observation refers to time period $t$. Following Ma and Riordan (1997), if the individual is ill and decides not to have treatment, the (c) RAND 2003. 
utility function will be given by

$$
U\left(y-p, s_{t}\right)=U(y-p)-s_{t}^{\gamma},
$$

whereas if she decides to have treatment, then the utility will be given by

$$
U\left(y-p-k * c_{t}, 0\right)=U\left(y-p-k * c_{t}\right) .
$$

Notice that the health penalty threshold, $\tilde{s}(c)$, defined by the above utility function changes with income. Consequently health care demand changes with income, i.e., the model exhibits income effects. The parameter $\gamma$ is the elasticity of the nonmonetary part of the utility with respect to the health penalty shock. I still must give a functional form for $U(\cdot)$. The exponential utility function is very convenient for my purposes. Ferrall and Shearer (1999) comment that from a computational standpoint, the exponential utility is perhaps the only feasible functional form when solving the principal-agent problem. ${ }^{14}$ Support to the exponential utility is given by Manning and Marquis (1996) and Marquis and Holmer (1996). Also using data from the RAND HIE experiment, they both argue in favor of the constant absolute risk-aversion hypothesis. ${ }^{15}$ Therefore, based on both the complexities that arise using different specifications and the support found in favor of the constant absolute risk-aversion hypothesis, I will use

$$
U(z)=-\exp (-\theta z)
$$

where $\theta$ stands for the constant absolute risk-aversion coefficient. Marquis and Holmer (1996) found that $\theta$ did not vary with income or other demographics, so I will not parameterize it as a function of individual characteristics. I will use Marquis and Holmer's estimate of $\theta$ (.00309 in 1973 dollars, .000727 in 2002 dollars) for the estimation. I will discuss this issue in the subsection devoted to identification.

The rest of the equations that close the model are the following:

$$
\begin{aligned}
s_{t} & =x_{s t} \beta_{s}+\mu_{s}+\varepsilon_{s t}, \\
\ln c_{t} & =\alpha \ln \left(s_{t}+1\right)+x_{c t} \beta_{c}+\mu_{c}+\varepsilon_{c t} \quad \text { if } s_{t}>0, \\
\operatorname{Pr}(T=1 \mid c) & =\operatorname{Pr}\left(s_{t}>\tilde{s}\left(c_{t}\right)\right),
\end{aligned}
$$

where $x_{s t}$ and $x_{c t}$ are two vectors of covariates, and $\beta_{s}$ and $\beta_{c}$ are respectively their conformable vector of parameters. The random vector $\left(\mu_{s}, \mu_{c}\right)$ controls for time-invariant unobserved heterogeneity. I assume $\left(\mu_{s}, \mu_{c}\right)$ is bivariate normal with zero mean. The parameters of its variance-covariance matrix are $\sigma_{\mu s}^{2}, \sigma_{\mu c}^{2}, \rho_{\mu}$. In an analogous way, $\left(\varepsilon_{s t}, \varepsilon_{c t}\right)$ is also assumed bivariate normal with zero mean and variance-covariance parameters given by $\sigma_{\varepsilon s}^{2}, \sigma_{\varepsilon c}^{2}, \rho_{\varepsilon}$. Equation (5) gives the health penalty, and equation (6) refers to the cost per episode. Inside the logarithm of the left-hand side, I add one to the health penalty. This ensures that the cost increases with $\alpha$ for any $s_{t}>0$. The functional form above is convenient because the predicted cost is always positive for any value of the parameters. All the studies cited above that estimated cost equations also used a logarithm transformation.

By means of a change of variable I can obtain the joint density of $\left(s_{t}, c_{t}\right)$, conditional on both $\left(x_{s, t}, x_{c, t}\right)$ and $\left(\mu_{s}, \mu_{c}\right)$ when both dependent variables take positive values:

$$
\begin{aligned}
f\left(s_{t}, c_{t} \mid x_{s t}, x_{c t}, \mu_{s}, \mu_{c}\right) \\
=\frac{1}{c_{t} \sigma_{\varepsilon s} \sigma_{\varepsilon c}} * b\left(\frac{s_{t}-x_{s t} \beta_{s}-\mu_{s}}{\sigma_{\varepsilon s}}, \frac{\ln c_{t}-\alpha \ln \left(s_{t}+1\right)-x_{c t} \beta_{c}-\mu_{c}}{\sigma_{\varepsilon c}} ; \rho_{\varepsilon}\right),
\end{aligned}
$$

\footnotetext{
${ }^{14}$ Other authors who have used the exponential utility function are Townsend (1994), Mace (1991), Haubrich (1994), and Margiotta and Miller (2000).

${ }^{15}$ In their footnote 13, Marquis and Holmer (1996) provide additional references in favor of the constant absolute risk-aversion hypothesis coming from studies of the demand for health insurance.

(c) RAND 2003 .
} 
where $b\left(\cdot, \cdot ; \rho_{\varepsilon}\right)$ is the standardized bivariate normal with correlation coefficient equal to $\rho_{\varepsilon}$. Note that $\rho_{\varepsilon}$ measures how strongly the health penalty shock is related to the cost shock. In particular, if $\rho_{\varepsilon}$ were 1 , then one could recover the exact value of $s_{t}$ from the observed $c_{t}$. Consequently, $\rho_{\varepsilon}$ measures the extent of information asymmetry. Further details will be given in Section 7.

The likelihood function. Estimation will be done by simulated maximum likelihood; here I give its formulation. Whether the individual had treatment or not provides different information. For individuals with treatment, I can observe the treatment cost. However, I cannot observe it for individuals who were ill but decided not to have treatment. This is a sample selection issue that the model must accommodate.

The likelihood function for individual $i$, for period $t$, conditional on time-invariant unobserved heterogeneity, if she had treatment $\left(T_{i t}=1\right)$ at a cost $c_{i t}>0$, is

$$
L_{1 i t}=\int_{\tilde{s}_{j}\left(c_{i t}\right)}^{+\infty} f\left(s_{i t}, c_{i t} \mid x_{s i t}, x_{c i t}, \mu_{s}, \mu_{c}\right) \partial s_{i t}, \quad j=I, N I,
$$

where $f(\cdot \mid \cdot)$ is the joint density $\left(s_{i t}, c_{i t}\right)$ as in (8). The integration limits correspond to the area at which it is optimal to have treatment when costs are $c_{i, t}$. As given by (3), this occurs when the health penalty is large enough.

The likelihood function for individual $i$ if she did not have treatment $\left(T_{i t}=0\right)$ is

$$
L_{0 i t}=\Phi\left(-\frac{x_{s i t} \beta_{s}-\mu_{s}}{\sigma_{\varepsilon s}}\right)+\int_{0}^{+\infty} \int_{0}^{\tilde{s}_{j}\left(c_{i t}\right)} f\left(s_{i t}, c_{i t} \mid x_{s i t}, x_{c i t}, \mu_{s}, \mu_{c}\right) \partial s_{i t} \partial c_{i t}, \quad j=I, N I
$$

where $\Phi(\cdot)$ denotes the cumulative distribution function of the standardized normal. The first term is the probability of not being ill, while the second is the probability of being ill but with a health penalty not large enough to offset the out-of-pocket costs. The cost has to be integrated out, since it is not observed for those who did not have treatment.

The likelihood function for individual $i$ and period $t$, conditional on $\left(\mu_{s}, \mu_{c}\right)$, is given by

$$
L_{i t}\left(\mu_{s}, \mu_{c}\right)=1\left[T_{i t}=1\right] *\left(L_{1 i t}\right)+\left[T_{i t}=0\right] *\left(L_{0 i t}\right) .
$$

Consequently, the likelihood function is obtained by integrating out the time-invariant unobserved heterogeneity across the time periods available to each individual: $q_{i}$, that is,

$$
\ln L=\sum_{i=1}^{N} \ln \left(\int \prod_{t=1}^{q_{i}} L_{i t}\left(\mu_{s}, \mu_{c}\right) d F\left(\mu_{s}, \mu_{c}\right)\right) .
$$

Computation of the log-likelihood function requires evaluation of four integrals, which is computationally intensive. Details of the computation of the likelihood and other econometric issues are in the Appendix.

Identification. In my model, the individual decides whether or not to seek care. This is a discrete-choice problem. As in any discrete-choice problem, the scale is not identified. For instance, in a probit model it is standard to fix the variance of the error term to one in order to estimate the rest of the parameters. Here, I fix the risk-aversion parameter using the estimate by Marquis and Holmer (1996); this should be a good enough approximation to the risk-aversion parameter of my dataset, since they estimated this parameter for the same dataset and used the same utility function. ${ }^{16}$

${ }^{16}$ In this and other issues, my analysis clearly benefits from extensive work that has been performed using the RAND HIE data. 
Another important issue is the identification of both $\rho$ and $\alpha$. For this section only I use the cost function

$$
\ln c_{t}=\alpha s_{t}+x_{c t} \beta_{c}+\varepsilon_{c t},
$$

which uses a log-linear specification rather than log-log. This is to emphasize that my identification argument does not depend on functional-form restrictions. I have checked that the simulations below also hold for the cost function used in the estimation, the log-log cost function. For the sake of simplicity, I omit the time-invariant unobserved heterogeneity terms. To facilitate the discussion, I introduce the following notation:

$$
E\left(\ln \left(c_{t}\right) \mid X_{s t}, X_{c t}, T_{t}=1, k=0\right)=A C_{\alpha, \rho_{\varepsilon}}(k=0)
$$

and

$$
E\left(\ln \left(c_{t}\right) \mid X_{s t}, X_{c t}, T_{t}=1, k>0\right)=A C_{\alpha, \rho_{\varepsilon}}(k>0) .
$$

I first look at the group of people with zero copayment rate. Because they do not pay anything, they do not compare health penalty and costs when deciding about having treatment. This makes the observed cost function easy to analyze for this group of people. From equation (12), it is easy to see that cost will increase in both $\rho_{\varepsilon}$ and $\alpha$ for the group of people with zero copayment, since they do not censor any of the positive draws of cost. They just have treatment whenever they are ill. An increase in $\alpha$ directly increases the cost. When the individual is ill, $\varepsilon_{s t}$ is high, so an increase in $\rho_{\varepsilon}$ will increase the likelihood of large draws of $\varepsilon_{c t}$. The formal expression for average cost conditional on having treatment for the consumers with zero copayment is

$$
A C_{\alpha, \rho_{\varepsilon}}(k=0)=X_{c t} \beta_{c}+\alpha \sigma_{\varepsilon s}\left(\frac{X_{s t} \beta_{s}}{\sigma_{\varepsilon s}}\right)+\frac{\phi\left(\frac{X_{s t} \beta_{s}}{\sigma_{\varepsilon s}}\right)}{\Phi\left(\frac{X_{s t} \beta_{s}}{\sigma_{\varepsilon s}}\right)}\left[\alpha \sigma_{\varepsilon s}+\rho_{\varepsilon} \sigma_{\varepsilon c}\right],
$$

where $\phi$ and $\Phi$ are, respectively, the density and cumulative distribution function of the standardized normal. This equation resembles the Heckman (1979) sample selection model except for the additional complication that $\alpha$ is not zero. Here, exclusion restrictions in $X_{c t}$ will not be enough to identify the model. This is because there are infinite combinations of $\alpha$ and $\rho_{\varepsilon}$ that are compatible with a given value of $A C_{\alpha, \rho_{\varepsilon}}(k=0)$. As we will see, it is crucial for the identification to have people with exogenously different copayment rates.

In what follows, I analyze how the information on people with other copayment rates contributes to the identification. First, however, we must understand that $\alpha$ and $\rho_{\varepsilon}$ must follow a decreasing relation to be compatible with a given value of $A C_{\alpha, \rho_{\varepsilon}}(k=0)$. In particular, for each value of $\alpha$ there is one and only one value of $\rho_{\varepsilon}$ that is compatible with the given value of $A C_{\alpha, \rho_{\varepsilon}}(k=0)$. The higher $\alpha$ is, the smaller $\rho_{\varepsilon}$ has to be to obtain the same value of $A C_{\alpha, \rho_{\varepsilon}}(k=0)$. This is because (13) increases in both $\alpha$ and $\rho_{\varepsilon}$. So the task is to explain how the information on consumers with positive copayments will tell us which particular combination of $\alpha$ and $\rho_{\varepsilon}$ will prevail in my model, out of those that are consistent with the given value of $A C_{\alpha, \rho_{\varepsilon}}(k=0)$. The intuition is clear if we look at two extreme cases: (i) $\alpha$ is high and $\rho_{\varepsilon}$ is close to zero, and (ii) $\alpha$ is close to zero and $\rho_{\varepsilon}$ is close to one.

If $\alpha$ is high and $\rho_{\varepsilon}$ is close to zero, there are a considerable number of large draws of $c_{t}$ that come from large draws of $\varepsilon_{c t}$ but not from high draws of $\varepsilon_{s t}$. Notice that these combinations are quite likely as $\rho_{\varepsilon}$ is close to zero. As health penalty shocks are not particularly high but costs are, then consumers with positive copayments will not ask for treatment. Consequently, these draws of $c_{t}$ will not be observed. Hence $A C_{\alpha, \rho_{\varepsilon}}(k>0)$ will be particularly low compared to $A C_{\alpha, \rho_{\varepsilon}}(k=0)$, as individuals with positive copayments will not have treatment for a large fraction of large draws of $c_{t}$. 
TABLE 2 Simulated Observed Costs for Different Combinations of $\alpha$ and $\rho$

\begin{tabular}{cccccc}
\hline & \multicolumn{2}{c}{$\alpha=3.34, \rho=0$} & & \multicolumn{2}{c}{$\alpha=0, \rho=.9$} \\
\cline { 2 - 3 } \cline { 5 - 6 } Copayment rate $(k)$ & Average & Standard Deviation & & Average & Standard Deviation \\
\hline 0 & 139.2 & 100.9 & & 139.3 & 25.9 \\
.25 & 118.9 & 49.2 & & 157.9 & 31.3 \\
.5 & 101.9 & 36.4 & & 163.9 & 31.6 \\
.95 & 83.6 & 26.32 & & 168.3 & 32.6 \\
\hline
\end{tabular}

Note: Simulated using log-linear cost function. Costs are valued in 2002 dollars.

On the other hand, if $\alpha$ is close to zero and $\rho_{\varepsilon}$ is close to one, large draws of $c_{t}$ have to come from large draws of $\varepsilon_{c t}$ due to the small value of $\alpha$. Given that $\rho_{\varepsilon}$ is large, large draws of $\varepsilon_{c t}$ are jointly obtained with large draws of $\varepsilon_{s t}$. Because the health penalty shocks are high, consumers with positive copayments will be willing to pay for treatment. Consequently, high values of $c_{t}$ would be more likely to be observed for this group of people than if $\alpha$ were high and $\rho_{\varepsilon}$ were close to zero. Consequently, $A C_{\alpha, \rho_{\varepsilon}}(k>0)$ will not be as low as the previous case, and it might even become larger than $A C_{\alpha, \rho_{\varepsilon}}(k=0)$.

The mathematical complexity of the problem prevents me from giving a formal proof of the argument. However, Table 2 provides a simulation to support it. It shows the results for two extreme cases: the first one is for $\alpha=3.34, \rho_{\varepsilon}=0$, and the second one is for $\alpha=0, \rho_{\varepsilon}=.9 .{ }^{17}$ Notice that the average cost conditional on treatment is decreasing in the copayment rate for the first case and increasing for the second one, while $A C_{\alpha, \rho_{\varepsilon}}(k=0)$ is the same, up to simulation error, in both cases. Hence the results of the simulation confirm my argument in the three previous paragraphs. The two combinations of $\left(\alpha, \rho_{\varepsilon}\right)$ seen in Table 2 belong to the infinite possible combinations of $\left(\alpha, \rho_{\varepsilon}\right)$ that are compatible with the same value of $A C_{\alpha, \rho_{\varepsilon}}(k=0)$, though they provide very different results on how the cost conditional on treatment changes across copayment rates. The relation shown in Table 2 is smooth. For instance, for intermediate values of $\left(\alpha, \rho_{\varepsilon}\right)$ I obtain a decreasing profile but not as strong a one as in in Table 2. Though intuition might make us think that average conditional cost should always decrease across copayment rates, both the simulations and the expression in (4) make clear that this is not necessarily the case.

Table 2 can be used to show another source of identification-how the variance of observed costs changes across copayment rates. When $\rho_{\varepsilon}=.9$, the standard deviations of the observed costs are very similar across copayment rates. This is because a large shock of $\varepsilon_{s t}$ (illness episode) translates to a large shock of $\varepsilon_{c t}$. This reduces the variance of $\varepsilon_{c t}$ across all copayment rates. However, when $\rho_{\varepsilon}=0$, the occurrence of illness does not influence the variance of $\varepsilon_{c t}$. Consequently, only small values of $c_{t}$ will be observed for those with high copayment rates. This reduces the variance of observed costs for those with high copayment rates, but not for those with zero copayment rates. For them we observe both small and large values of $c_{t}$, and consequently the variance of observed costs is much larger for this group than for the one with .95 copayment rate.

\section{Descriptive analysis}

This section focuses on Tables 3 and 4, which show the results of a descriptive analysis of the data. Table 3 shows how frequency of episodes treated varies with copayment rates. Those who enjoy a zero copayment rate seek care more often than those who face cost-sharing contracts. Table 4 shows the estimates of a standard multiperiod probit model for Treatment as a dependent

17 The rest of the parameters are $X_{s t} \beta_{s}=-.56, X_{c t} \beta_{c}=.94, \sigma_{\varepsilon s}^{2}=.29, \sigma_{\varepsilon c}^{2}=2.25$, and $\gamma=2.45$. I chose them based on the results of our model and have checked to confirm that my results are robust to other parameter values. These parameter values give the results in 1973 dollars. 
TABLE 3

Distribution of Episodes Treated

\begin{tabular}{lccc}
\hline Copayment & $\begin{array}{c}\text { Number of Observations } \\
\text { Person-Years }\end{array}$ & $\begin{array}{c}\text { Percentage of } \\
\text { Sample Treated }\end{array}$ & $\begin{array}{c}\text { Mean of } \\
\text { Observed Cost }\end{array}$ \\
\hline 0 & 2,955 & $16.98 \%$ & 155.2 \\
$25 \%$ & 1,724 & $13.22 \%$ & $(267.6)$ \\
$50 \%$ & 550 & $11.27 \%$ & $(235.7)$ \\
$\geq 95 \%$ & 1,551 & & 117.1 \\
Observations & 6,780 & $10.38 \%$ & $178.9)$ \\
\hline
\end{tabular}

Note: Standard deviations are in parentheses. Costs are valued in 2002 dollars.

variable. Since I use panel data, I can control for time-invariant individual heterogeneity using random effects. This probit model is not related to the theoretical model explained above. It is just a statistical model used as a descriptive device. For the estimation of this model I used the same illness spells employed for the estimation of the structural model. The results on the copayment rates supply basically the same information as in Table 3. The coefficients of the dummy variable for copayment groups are negative and statistically significant, indicating that copayment influences the probability of having treatment in the expected way. Apart from copayments, other significant variables are Female, Health, Disease, Age, and Charleston. ${ }^{18}$ It is worth mentioning that once I control for Health and Disease, Age decreases the probability of having an episode treated.

Valuable information about income effects is gained through analyzing the results in Table 4. Income increases the probability of having treatment for those who have to pay for medical

TABLE 4 Estimates of Multiperiod Probit Model for $T_{t}=1,0$

\begin{tabular}{lcc}
\hline & Coefficient & Standard Error \\
\hline Constant $^{\mathrm{a}}$ & $-.7857^{*}$ & .1160 \\
Health $^{\mathrm{a}}$ & $-.0695^{*}$ & .0236 \\
Female $^{\mathrm{a}}$ & $.2041^{*}$ & .0469 \\
Disease $^{\mathrm{a}}$ & $.0913^{*}$ & .0253 \\
Age $* 1 e-2-.4686^{*}$ & .2018 \\
Appointment $^{\mathrm{a}}$ & .0370 & .0221 \\
Education $^{\mathrm{a}}$ & .0023 & .0245 \\
Charleston & $-.3556^{*}$ & .0970 \\
$1[$ Copay $=.25]$ & $-.2931^{*}$ & .0744 \\
$1[$ Copay $=.5]$ & $-.4202^{*}$ & .0957 \\
$1[$ Copay $\geq .95]$ & $-.4619^{*}$ & .0742 \\
Inc $* 1 e-3$ & -.0194 & .0816 \\
Inc $* 1[$ Copay $>0] * 1 e-3$ & $.2201^{*}$ & .1034 \\
S.D. Unob heterog & $.3501^{*}$ & .0516 \\
Log-likelihood & & $-2,657.07$ \\
\hline
\end{tabular}

Note: 1 [condition $]=1$ if condition is true, 0 otherwise. Inc is valued in 1973 dollars for the estimation.

*Significantly different from zero at the $95 \%$ confidence level.

${ }^{a}$ Estimates refer to the standarized variables.

${ }^{18}$ The estimation included time dummies and dummies for each town, but Charleston was the only significant one. Time dummies were not statistically significant either. 
treatment (those with $1[$ Copay $>0]=1$ ). Consequently, it is clear from the descriptive analysis that the data exhibit income effects. Manning and Marquis (1996) and Cardon and Hendel (2001), among others, have also found evidence of income effects. As highlighted in the Introduction, previous approaches that did not use the principal-agent paradigm might have neglected the role played by income effects when solving for the optimal contract.

Table 3 shows the average treatment cost conditional on having treatment. The data show that average cost conditional on treatment decreases with copayment rates. However, this difference is not significantly different from zero at the usual confidence levels. The same conclusion was found by Keeler and Rolph (1988) and Newhouse et al. (1993) using data from the full sample period, not only the first month as I do here. For further reference, the 50th, 75th, and 95th percentiles of the observed cost distribution for those with zero copayment are $\$ 74.4, \$ 155.8$, and $\$ 535.2$ respectively (2002 dollars). These numbers are consistent with the decision not to include inpatient episodes.

\section{Structural estimation results}

- Model results. This section discusses the estimation of the structural model. I first comment on the results of a large specification, the results of which are not shown here but are available upon request. ${ }^{19,20}$ I found $\alpha$ to be negative $(-1.95)$ and not statistically significant different from zero $(t$-value $=.88)$. I also tried a log-linear specification but found a negative point estimate. Given that it is quite implausible to think that costs decrease with health penalty, the negative sign could be an indication that the size of the true effect must be quite small, so I estimated the model with $\alpha$ restricted to zero. This does not mean that health penalty does not influence costs. Costs and health penalty are still related through their correlation between unobservables, $\varepsilon_{s t}$ and $\varepsilon_{c t}$. Hence I proceeded to estimate a more parsimonious specification of the model in which $\alpha$ was fixed to zero, Education and Female did not enter into the cost equation, and only some of the year and site dummies were included - those that were significant or were closer to being individually significant in the large specification. The results of this more parsimonious specification are reported in Table 5. ${ }^{21}$ The coefficients reported refer to the model estimated using Income and Costs valued in 1973 dollars.

As shown by the results in Table 5, better health status (large Health) reduces both health penalty and costs. Female shifts the mean of the health penalty equation upward. The more illnesses a person suffers (larger Disease), the larger the health penalty, though no significant effect is found in the cost of treating a single episode. Similar to the multiperiod probit model results, once I control for Health and Disease, Age decreases the level of health penalty. The sign of Appointment is consistent with the idea of a supply capacity indicator. The larger Appointment is, the less a person has to wait for a medical appointment. Hence, relative supply capacity is larger and thus costs might be smaller. Notice that this is consistent with the results on Table 4. However, the coefficient is not statistically significantly different from zero at the $95 \%$ confidence level.

As expected, the correlation parameters are positive and significant, indicating that health penalty and costs are positively related. It is worth mentioning that the correlation between $\left(\varepsilon_{t s}, \varepsilon_{t c}\right)$ is quite high (.79), even if we are controlling for time-invariant correlated individual heterogeneity. This means that the health penalty shock can be moderately well predicted by observing the costs, which reduces the extent of informational asymmetry. Using the analogy with an $R^{2}$ measure,

${ }^{19}$ In this large specification I included both Female and Education in the cost equation, but they were not statistically significantly different from zero. I also included all year and site dummies in both equations. I excluded both Education and Appointment from $X_{s t}$.

${ }^{20}$ In this large specification I excluded Age from $X_{c t}$. Keeler and Rolph (1988) and Newhouse (1993) give results of an equation for observed cost for acute episodes. They do not find significant variation in Age for people between 18 and 65 , once the effect of other covariates has been taken into account.

${ }^{21}$ The parsimonious model has 22 parameters to estimate and the large one has 41 . The first model took about seven days to estimate, and the second took about two weeks. The $P$-value of the log-likelihood ratio test is .28 , so the restricted model is not rejected at the $95 \%$ confidence level.

(C) RAND 2003 


\begin{tabular}{|c|c|c|}
\hline & Health Penalty Equation $\left(\beta_{s}\right)$ & Cost Equation $\left(\beta_{c}\right)$ \\
\hline \multirow[t]{2}{*}{ Constant } & $-.479^{*}$ & $.928^{*}$ \\
\hline & $(.138)$ & $(.276)$ \\
\hline \multirow[t]{2}{*}{ Health $^{\mathrm{a}}$} & $-.040^{*}$ & $-.152^{*}$ \\
\hline & $(.016)$ & $(.048)$ \\
\hline \multirow[t]{2}{*}{ Female } & $.115^{*}$ & 0 \\
\hline & .040 & $(-)$ \\
\hline \multirow[t]{2}{*}{ Disease $^{\mathrm{a}}$} & $.048^{*}$ & .027 \\
\hline & $(.020)$ & $(.045)$ \\
\hline \multirow[t]{2}{*}{ Age $* 1 e-2$} & $-.276^{*}$ & 0 \\
\hline & $(.121)$ & $(-)$ \\
\hline \multirow[t]{2}{*}{ Appointment ${ }^{\mathrm{a}}$} & 0 & -0.049 \\
\hline & $(-)$ & $(.037)$ \\
\hline \multirow[t]{2}{*}{ Seattle } & 0 & $.242^{*}$ \\
\hline & $(-)$ & $(.088)$ \\
\hline \multirow[t]{2}{*}{ Franklin } & -.048 & 0 \\
\hline & $(.030)$ & $(-)$ \\
\hline \multirow[t]{2}{*}{ Charleston } & $-.184^{*}$ & -.308 \\
\hline & $(.067)$ & $(.162)$ \\
\hline \multirow{2}{*}{ Year78 } & -.028 & 0 \\
\hline & $(.023)$ & $(-)$ \\
\hline \multirow[t]{2}{*}{ Year80 } & -.050 & 0 \\
\hline & $(.035)$ & $(-)$ \\
\hline \multirow[t]{2}{*}{$\alpha$} & & 0 \\
\hline & & $(-)$ \\
\hline \multirow[t]{2}{*}{$\sigma_{\varepsilon}$} & $.541^{*}$ & $1.503^{*}$ \\
\hline & $(.153)$ & $(.115)$ \\
\hline \multirow[t]{2}{*}{$\sigma_{\mu}$} & $.204^{*}$ & $.448^{*}$ \\
\hline & $(.061)$ & $(.117)$ \\
\hline \multicolumn{3}{|c|}{ Correlation parameters } \\
\hline \multirow[t]{2}{*}{$\rho_{\varepsilon}$} & $.796^{*}$ & \\
\hline & $(.066)$ & \\
\hline \multirow[t]{2}{*}{$\rho_{\mu}$} & $.860^{*}$ & \\
\hline & $(.143)$ & \\
\hline \multicolumn{3}{|c|}{ Utility function parameters } \\
\hline \multirow[t]{2}{*}{$\theta * 1 e+3$} & 3.0992 & \\
\hline & $(-)$ & \\
\hline \multirow[t]{2}{*}{$\gamma$} & $2.452^{*}$ & \\
\hline & $(.456)$ & \\
\hline Log-likelihood & $-4,103.66$ & \\
\hline
\end{tabular}

Notes: Asymptotic standard errors are in parentheses. A (-) indicates that the value of the coefficient was fixed during the estimation.

*Significantly different from zero at the $95 \%$ confidence level.

${ }^{\text {a }}$ Estimates refer to the standardized variables.

about two-thirds of the health penalty shock variance would be explained by the costs. ${ }^{22}$ The high correlation of .79 is not due to restricting $\alpha$ to zero. In the unrestricted model, the estimated correlation was 89 .

Model evaluation and robustness checks. To assess the validity of the model, I compare

\footnotetext{
${ }^{22}$ Given my parametric assumptions and parameter estimates, one can compute the expected value of the health penalty given some realization of costs. For instance, for an individual with zero copayment and mean covariates, if we observe that the logarithm of the cost is larger than its mean plus one standard deviation, then the predicted value of the health penalty shock is 1.48 standard deviations of its unconditional mean.
} 
TABLE 6 Predicted Values of Endogenous Variables Using Table 5 Estimates

\begin{tabular}{lccccccc}
\hline & \multicolumn{3}{c}{ Frequency of Treatment $(\%)$} & & \multicolumn{3}{c}{ Observed Costs } \\
\cline { 2 - 3 } \cline { 7 - 9 } Copayment & $L_{\text {inf }}$ & Mean & $L_{\text {sup }}$ & & $L_{\text {inf }}$ & Mean & $L_{\text {sup }}$ \\
\hline 0 & 15.4 & 16.7 & 18.6 & & 125.5 & 140.3 & 174.8 \\
$25 \%$ & 12.0 & 13.1 & 14.7 & & 123.3 & 143.7 & 174.4 \\
$50 \%$ & 10.9 & 12.0 & 13.5 & & 108.8 & 133.5 & 156.9 \\
$\geq 95 \%$ & 9.25 & 10.6 & 11.9 & & 97.8 & 133.5 & 155.2 \\
\hline
\end{tabular}

Notes: $L_{\text {inf }}$ and $L_{\text {sup }}$ refer, respectively, to the inferior and superior limit of the $95 \%$ confidence interval. Costs are valued in 2002 dollars.

the predictions for the dependent variable from the estimated model (Table 6) with the real data (Table 3). For this task, I have used the estimates shown in Table 5 to predict the frequency of treatment and observed costs from the structural model. I also report approximate $95 \%$ confidence intervals for the predictions computed by obtaining random draws from the asymptotic distribution of the estimates.

For the frequency of treatment, comparing the mean prediction in Table 6 with the third column of Table 3 shows that the model does a good job of fitting the actual frequency of treatment across copayment groups. Moreover, the real values are well within the $95 \%$ confidence interval for the prediction. The bigger difference in the actual frequency of treatment is between the $0 \%$ and the $25 \%$ copayment groups (16.9 versus 13.2 in Table 3 ), with little difference in frequency between the $50 \%$ and the $95 \%$ copayment groups (11.2 versus 10.3$)$. This nonlinearity has been previously documented in Newhouse et al. (1993). Notice that the mean predictions in Table 6 do reproduce this nonlinear effect. It is promising that a structural model with a linear budget constraint can fit the nonlinearity displayed by the actual frequency of treatment. The parameter $\gamma$ is important in producing this nonlinearity. Moreover, some of the confidence intervals do not even overlap, which shows that the predictions are quite accurate. As expected, the results for the observed cost of treatment are not that good. Out of the sample size of 6,780, we have only 953 episodes with treatment, so we cannot learn as much from the costs as we learn from the treatment frequencies. Still, the actual means in Table 3 lie within the confidence intervals in Table 6 for all the copayment groups. The mean predictions do not considerably differ among copayment groups. This is consistent with the fact that there are no statistically significant differences in average costs across copayment rates.

Participation incentives were paid to minimize the risk of attrition bias in the experiment. Manning et al. (1987) mention that both refusal to participate and attrition seemed to be random. Newhouse et al. (1993) compare the characteristics of the participants on the free care plan and other plans using 20 different variables. The only statistically significant difference at the $95 \%$ level was found for sex, which I control for in the analysis. I still perform a robustness check to confirm that attrition bias is not a major problem. To do that, I estimated the cross-section version of the structural model using just the first year of the experiment. All the panel data point estimates of the slopes fell within the $95 \%$ confidence interval estimated using the first year cross-section.

\section{The principal-agent problem}

Because my theoretical model is not dynamic, in the remainder of the article I omit any subscript $t$. In our problem, moral hazard will emerge because the health penalty variable $s$ is noncontractible, that is, the insurance contract cannot be contingent on the value taken by $s$. That might occur because it cannot be verified by a third party, or it could be too costly to do so. To understand the moral hazard problem, assume that the individual faces a complete insurance contract. Hence the individual will look for treatment even if the cost $c$ is very large and the health penalty $s$ is positive but very small. Consequently, the insurance premium for such a contract would be relatively high to cover treatment for this large draw of $c$. The individual would be 
better off committing not to have treatment when $c$ is large and $s$ is small so the insurance premium would be much smaller and could offset the small health penalty $s$. If the contract were contingent on both $s$ and $c$, then the individual would easily commit to that policy by signing a contract that would not reimburse treatment when $s$ is low and $c$ is high. But if the contract cannot be contingent on $s$, then the individual cannot sign such a contract, which results in a welfare loss. If $s$ is not contractible, it might be optimal to use monetary incentives as an imperfect commitment device so that consumers do not demand treatment when $c$ is large and $s$ is small.

I use the estimates of the parameters of the model to solve for the optimal contracts. That is the advantage of structural estimation. Because of the experimental design of the data, I did not need to assume that contracts were optimal when estimating the parameters. I assume that the individual signs the contract before she knows the realizations of $(s, c)$. As in the previous sections, I assume that the individual knows the realizations of $(s, c)$ when she decides whether or not to have treatment. I follow Ma and Riordan $(1997,2002)$ very closely when setting up the maximization problems. However, unlike Ma and Riordan, I have to deal with the random nature of the cost function.

First-best problem. In the first-best problem, both costs and health penalty are contractible. The first-best contract should specify the insurance premium, the out-of-pocket payment function, and the combinations $(s, c)$ for which this out-of-pocket payment function applies. In the first-best problem there is no market failure, hence optimal insurance should equalize marginal utility of income across states of nature. In my model, the realizations of $(s, c)$ represent the states of nature. Consequently, the marginal utility of income should be independent of the realizations of $(s, c)$. Given the concavity of the utility function, this implies that available income should change with neither $s$ nor $c$. As out-of-pocket payment would be paid only if $s>0$, then the optimal contract should exhibit zero out-of-pocket payment in order to have constant available income across states of nature. In particular, this means that if treatment is obtained, the insurance company will fully reimburse (complete insurance) the individual for the costs.

I still must discuss when treatment will be obtained. In the first-best problem, the consumer will not be free to choose whether or not to have treatment. The first-best contract will specify when treatment is obtained according to the realizations of $(s, c)$. It cannot be optimal to have treatment when cost is large and health penalty is low. Notice also that if it is optimal to have treatment when cost is $c$ and health penalty is $s$, then it will also be optimal to have treatment for higher values of $s$ at the given $c$. Hence I can define the function $O(c)$ that gives the minimum level of $s$ for which it is optimal to have treatment when costs are $c$. With this in hand, I can set up the first-best problem as

$$
\begin{aligned}
& \max _{\{p, O(c)\}} \operatorname{Pr}(s<0 \mid \bar{s}) * U(y-p, 0)+\int_{0}^{+\infty} \int_{0}^{O(c)} U(y-p, s) g_{s, c \mid \bar{s}, \bar{c}}(s, c) \partial s \partial c \\
& \quad+\int_{0}^{+\infty} \int_{O(c)}^{+\infty} U(y-p, 0) g_{s, c \mid \bar{s}}(s, c) \partial s \partial c \\
& \text { subject to } p=\int_{0}^{+\infty} \int_{\mathrm{O}(\mathrm{c})}^{+\infty} \mathrm{c} * \mathrm{~g}_{\mathrm{s}, \mathrm{c} \mid \overline{\mathrm{s}}, \overline{\mathrm{c}}}(\mathrm{s}, \mathrm{c}) \partial \mathrm{s} \partial \mathrm{c} .
\end{aligned}
$$

The first two lines are the consumer expected utility. The premium is denoted by $p$. The first term represents the utility in case illness will not occur. The second term gives the expected utility when the consumer is ill but treatment is not obtained. The third term is the expected utility when treatment is obtained. The third line specifies that the premium should be actuarially fair. To solve the first-best problem I must find the insurance premium level and the function $O(c)$ that gives the minimum level of health penalty at which treatment is obtained. The way I approach the problem is to parameterize $O(c)$ in a flexible way and then find the value of the parameters that solve the 
maximization problem. ${ }^{23}$ I have chosen the following parameterization:

$$
O\left(c \mid a_{0}, a_{1}, a_{2}, a_{3}\right)=\max \left\{0, a_{0}+a_{1} * c+a_{2} * c^{2}+a_{3} * c^{3}\right\} .
$$

The argument of $O(c)$ is a polynomial that allows the function to follow a flexible profile on $c$. I increased the polynomial degree up to a third order, at which point the results for larger polynomial degrees were very similar. Numerical approximations based on polynomial expansions are known to be sensitive to initial conditions. I used Simulated Annealing as the maximization routine. This is a very robust, though computationally intensive, random search algorithm that is able to escape from local optima (Goffe, Ferrier, and Rogers, 1994). ${ }^{24}$ It can also handle nondifferentiable problems. I have computed the solution for the individual with values of $X_{s t}$ and $X_{c t}$ set at their mean values and $\mu_{s}$ and $\mu_{c}$ set to their unconditional means (0). Notice that for the solution to the principal-agent problem, $\mu_{s}$ and $\mu_{c}$ have the same interpretation as $X_{s t}$ and $X_{c t}$, since they do not add uncertainty at the individual level. The only difference is that $X_{s t}$ and $X_{c t}$ are known by the econometrician while $\mu_{s}$ and $\mu_{c}$ are not, but all of them are individual characteristics that are common knowledge in the principal-agent relation.

The solution to the problem is $p=12.80, a_{0}=.108, a_{1}=7.21 \mathrm{E}-04, a_{2}=-3.56 \mathrm{E}-07$, and $a_{3}=5.213 \mathrm{E}-11$ (for $c$ valued in 2002 dollars). As expected, for the relevant range of $c$, the function is always increasing in $c$. That is, the higher the cost, the higher the health penalty must be in order to be optimal to obtain treatment. I use the function $O(c)$ when computing the welfare loss below.

Second-best problem. The second-best problem assumes that the insurer can contract on just the costs and not on the health penalty shock. Consequently, in the second-best problem no argument of the contract can depend on the health penalty shock. This informational asymmetry is the source of moral hazard. ${ }^{25}$ Moreover, since there is noise between these two random variables ( $\varepsilon_{s}$ and $\varepsilon_{c}$ are not perfectly correlated), the insurer cannot perfectly recover the health penalty from the observed cost. The second-best contract will specify a premium $p$ and a cost-sharing function $D(c)$ that will determine how much the individual will pay out of pocket for receiving medical treatment with $\operatorname{costs} c$. At the second-best, the insurer cannot design a region of $(s, c)$ for which the contract applies, since $s$ is not contractible. On the contrary, the insurer will take into account that the insured will behave according to her optimal decision rule (3).

The second-best problem is defined by

$$
\begin{aligned}
& \max _{\{p, D(c)\}} \operatorname{Pr}(s<0 \mid \bar{s}) * U(y-p, 0)+\int_{0}^{+\infty} \int_{0}^{\tilde{s}(c)} U(y-p, s) g_{s, c \mid \bar{s}, \bar{c}}(s, c) \partial s \partial c \\
& \quad+\int_{0}^{+\infty} \int_{\tilde{s}(c)}^{+\infty} U(y-p-D(c), 0) g_{s, c \mid \bar{s}}(s, c) \partial s \partial c, \\
& \text { subject to } p=\int_{0}^{+\infty} \int_{\tilde{\mathrm{s}}(\mathrm{c})}^{+\infty}(\mathrm{c}-\mathrm{D}(\mathrm{c})) \mathrm{g}_{\mathrm{s}, \mathrm{c} \mid \bar{s}, \overline{\mathrm{c}}}(\mathrm{s}, \mathrm{c}) \partial \mathrm{s} \partial \mathrm{c}, \\
& U(y-P, \tilde{s}(c))=U(y-p-D(c), 0) .
\end{aligned}
$$

${ }^{23}$ Dynamic programming models are commonly solved by parameterizing the policy function as I do here. In a dynamic programming context, this way of solving the problem is commonly called the projection method. I am not aware of any other application of this methodology in the principal-agent framework.

24 The coefficients of the polynomial are the inputs to the maximization routine. At each combination of polynomial coefficients, I solve the premium constraint numerically and then evaluate the objective function. I have benefited from the Simulated Annealing code written by E.G. Tsionas.

${ }^{25}$ I say this is a moral hazard problem since it is an informational asymmetry after the contract has been signed (Laffont and Tirole, 1993; Macho-stadler and Pérez-Castrillo, 2001). Because it is more an informational advantage than an action, other authors might call it hidden information.

(c) RAND 2003. 
The expected utility of the second-best problem is analogous to the first-best problem. Both the expected utility and the fair premium constraint take into account that the consumer will pay out of pocket. Equation (19) is the constraint that takes into account the individual's optimal decision about whether or not to have treatment. That is, this constraint gives the health penalty threshold as a function of $D(c)$. To solve for $D(c)$, I use a procedure analogous to the one used to solve the first-best problem, except that the function will take the parameterization

$$
D\left(c \mid a_{0}, a_{1}, a_{2}, a_{3}\right)=L\left(a_{0}+a_{1} * c+a_{2} * c^{2}+a_{3} * c^{3}\right) * c,
$$

where $L(\cdot)$ stands for the cumulative distribution function of the logistic. This parameterization has the advantage that it restricts the value of $D(c)$ to be between zero and $c$, since a cumulative distribution function always takes a value between zero and one. In this case a third-order polynomial was also enough to provide a good approximation, as the fourth and fifth polynomials gave very similar results. The solutions to the problem are $p=6.21, a_{0}=2.38, a_{1}=-9.917 \mathrm{E}-$ $03, a_{2}=1.106 \mathrm{E}-05$, and $a_{3}=-4.1 \mathrm{E}-09$ (for $c$ valued in 2002 dollars). Like $O(c), D(c)$ is also increasing in the relevant range of $c$.

The second column of Table 7 shows selected cost-sharing values. The percentage that the consumer pays out of pocket decreases from $88.1 \%$ when medical costs are $\$ 40$ to $38.4 \%$ when medical treatment costs are $\$ 600$ (2002 dollars). The out-of-pocket function, $D(c)$, shows a concave pattern that gives more coverage to the individual in case of higher costs. The premium that corresponds to the optimal contract is $\$ 6.21$. This is a small number because I consider only a limited set of episodes, those for acute conditions that do not need hospitalization and start in a given month. It might be argued that this contract is too complicated to be implemented. I also obtained more simple contracts: a copayment $(D(c)=k * c)$, a deductible $(D(c)=\min \{c, d\})$, and a piecewise linear contract $(D(c)=\min \{c, f+q(c-f), m\})$. The solutions are $k=.42$, $d=187, f=51.9, q=.52$, and $m=242.6$. All of them gave less utility than the polynomial approximation found before. However, the level of utility of the piecewise linear contract was found to be quite close to that of the polynomial approximation. In fact, the cost-sharing values of the second and third column of Table 7 are reasonably close. This piecewise linear profile is frequently observed in health insurance contracts: they do not provide coverage at low costs, they cover a fixed percentage for higher costs, and, when costs exceed an upper bound, the insurance company covers all the extra costs (Cutler and Zeckhauser, 2000).

To satisfy the model assumptions, I only used data on acute and chronic flare-up episodes. This means that not much information is available on expensive episodes. Consequently, my costsharing values for expensive episodes should be interpreted carefully. For the same reason, it is worthy to examine how this limited information on large-cost episodes influences my cost-sharing values for less-costly illness episodes. To explore this issue, I solved the second-best problem

TABLE 7 Selected Cost-Sharing Values Given by

Contracts $(D(c) / c * 100)$

\begin{tabular}{lcccc}
\hline & \multicolumn{3}{c}{ Income Effects } & No Income Effects \\
\cline { 2 - 4 } Costs $(c)$ & $\begin{array}{c}\text { 3rd Degree } \\
\text { Polynomial }\end{array}$ & $\begin{array}{c}\text { Piecewise } \\
\text { Linear }\end{array}$ & $\begin{array}{c}\text { 3rd Degree } \\
\text { Polynomial }^{\text {a }}\end{array}$ & $\begin{array}{c}\text { 3rd Degree } \\
\text { Polynomial }\end{array}$ \\
\hline 40 & 88.1 & 100 & 91.2 & 94.0 \\
80 & 84.0 & 83.1 & 83.2 & 92.0 \\
120 & 79.3 & 72.8 & 77.1 & 89.8 \\
200 & 69.1 & 64.4 & - & 85.1 \\
400 & 48.0 & 58.2 & - & 76.0 \\
600 & 38.4 & 40.4 & - & 75.1 \\
Premium & $\$ 6.20$ & $\$ 6.12$ & $\$ 0.76$ & $\$ 1.49$ \\
\hline
\end{tabular}

Note: Costs and premium are valued in 2002 dollars.

${ }^{\mathrm{a}}$ Cost density was truncated not to take values larger than $\$ 155.8$. 
using the original density function but truncated in costs. In particular, the density function was truncated not to take values of costs larger than $\$ 155.8$. This is the 75 th percentile of observed cost distribution for those with zero copayment. I also used a third-order polynomial to solve the second-best problem. The implied cost-sharing values are given in the fourth column of Table 7. The cost-sharing values of the truncated (fourth column) and untruncated (second column) solutions are quite similar, especially for treatment costs between $\$ 40$ and $\$ 120$. The optimal copayment when costs cannot be larger than $\$ 155.8$ is $82 \%$.

Even though extensive previous work used the RAND HIE data, it is difficult to compare my results with those in previous work. First, my model deals with illness episodes that start in a month, rather than all the illness episodes in a year. Second, I have included neither chronic expenditures, because they are not random, nor episodes that require hospitalization. I follow this focus because Besley (1988) points out that different health care services will require optimally different cost-sharing rules, since they have different elasticities. I have also done so in order to use episodes that are consistent with the basic assumptions of the model.

$\square \quad$ Moral hazard measure and welfare loss. In this subsection I will give a new empirical measure of moral hazard. Though it might be natural from a theoretical point of view, I am not aware of previous estimates of it. The health economics literature has traditionally relied on the elasticity of utilization with respect to copayment as a measure of moral hazard. This price elasticity measures an important aspect of moral hazard: how sensitive individuals are to incentives. However, it is not the only aspect to measure. Here I propose a new measure of moral hazard that is complementary to elasticity rather than a substitute for it. My measure is clearly linked to the informational content of contractible variables over noncontractible ones, and hence it is especially appealing when we look at the problem from the incomplete-markets or principal-agent paradigm. As Winter (2000) points out, if there is a deterministic relation between contractible and noncontractible variables, then there is no moral hazard and the first best can be achieved by means of a nonlinear contract. ${ }^{26}$ As pointed out at the beginning of this section, moral hazard arises because $s$ is noncontractible. If there is a deterministic relation between $c$ and $s$, however, then it is enough to sign a contract contingent on $c$. That is, the insurer can recover the value of $s$ from the observed $c$, meaning that the value of $s$ is no longer the insured's private information. This suggests $\operatorname{var}(s \mid c)$ as our moral hazard measure. If this variance were zero, then the relation between $s$ and $c$ would be deterministic. Given that in my model any uncertainty at the individual level is through $\varepsilon_{s}$ and $\varepsilon_{c}$, the moral hazard can be measured by $\operatorname{var}\left(\varepsilon_{s} \mid \varepsilon_{c}\right)$. Due to the bivariate normality assumption, $\operatorname{var}\left(\varepsilon_{s} \mid \varepsilon_{c}\right)=\sigma_{\varepsilon s}^{2}\left(1-\rho_{\varepsilon}^{2}\right)$. Hence if $\rho_{\varepsilon}=1$, then there would not be moral hazard. Notice that from the results in Table 5, we may reject the nonexistence of moral hazard at the $95 \%$ confidence level. Apart from the issue of rejecting or not rejecting the moral hazard hypothesis, it is clear that the value of $\rho_{\varepsilon}$ is important because it tells us how health penalty changes with costs. This is particularly important if nonlinear contracts are used. Although it is hard to interpret whether a value for $\rho_{\varepsilon}$ of .79 is high or low, it seems moderately close to one and hence the extent of moral hazard seems reduced. However, there is still significant informational asymmetry. Using the analogy with an $R^{2}$ measure, we can say that about two-thirds (approximately $.79^{2}$ ) of the variance of residual health penalty is explained by the cost, but one-third remains unexplained. ${ }^{27}$ I would like to highlight that the availability of my moral hazard measure is a product of my modelling choice to make a clear distinction between contractible and noncontractible variables.

A measure of the importance of the moral hazard problem can be obtained by computing the welfare loss due to moral hazard, that is, due to the noncontractability of the health penalty shock. I compute the compensating variation as the amount of income that must be subtracted from the

${ }^{26}$ That would occur independently of the elasticity value. Even if demand were very elastic, a deterministic relation between contractible and noncontractible variables would preclude the existence of moral hazard. That is why my measure is complementary to elasticity.

${ }^{27}$ In a linear model of residual health penalty over costs and a constant, the $R^{2}$ measure would give the fraction of the variance of residual health penalty explained by the costs. The $R^{2}$ is equal to the square of the correlation coefficient. 
consumer in order to obtain with the first-best contract the same expected utility level as from the second best. I find that the compensating variation is $\$ .68$, or $4.82 \%$ of the second-best expected health care expenditure (premium plus out-of-pocket payments). This seems to reinforce the idea that the moral hazard problem is not too large.

The elasticity of expected costs with respect to copayments has been the traditional measure of moral hazard. The reader might be interested in the values of these elasticities predicted by my model. This is easy to obtain given the information in Table 6 . The arc elasticity between the $0 \%$ and $25 \%$ copayment rate is -.108 , while it is -.243 for the $25 \%-95 \%$ range. These predictions are quite close to the Manning et al. (1987) results of -.13 and -.21 , respectively, for outpatient care reported in their Table 8. My estimate of the elasticity of expected costs with respect to income is .07 when copayment equals $12.5 \%$, and .26 when copayment equals $60 \%$.

$\square \quad$ Comparison with a model without income effects. In this subsection I compare my results with those of a model that does not take into account income effects. To do this comparison, I estimate the structural model using $U\left(Y-s^{\gamma}\right)$ as the utility function. Notice that the health penalty threshold, $\tilde{s}(c)$, defined by this utility function does not depend on income. There is an obvious caveat for this comparison. If the data exhibit income effects, as mine do, the estimates of a model without income effects are almost necessarily inconsistent. Hence, the cost-sharing values estimated using the model without income effects are also inconsistent. Thus, my comparison can only be interpreted in the following way: How would my results change if I had not considered the presence of income effects? Given the results in Section 5, one must clearly prefer the incomeeffects specification. However, I find the comparison of the contracts obtained under the two hypotheses interesting.

In principle, a first approximation to the problem could be obtained by computing the compensated elasticities of expected costs with respect to the copayment rate. In my model with income effects, the compensated price elasticities are almost identical to the uncompensated ones (the compensated ones are -.108 for the $0 \%-25 \%$ range, and -.241 for the $25 \%-95 \%$ range). The compensated and uncompensated elasticities are almost identical because the expected cost is around $1 \%$ of mean income (notice that the probability of any cost is around .13 and the probability mass for small costs is substantial). Consequently, a first approximation would tell us that income effects are not important in the determination of optimal cost-sharing values. However, I find below nonnegligible differences between the optimal cost-sharing values implied by the model with income effects and the model without income effects. This could be because the model without income effects gives inconsistent estimates. Another possible explanation is that the compensated elasticity is based on the share of expected cost on income, while it could be the share of realized costs on income that matters in the determination of cost-sharing values when a contract that conditions on cost (a nonlinear contract) is used. In fact, I find evidence of this by comparing the second and fifth colums of Table 7. The difference between the two cost-sharing values increases with the magnitude of costs. As one would expect, the larger the share of costs over income, the more important the income effect.

I would like to put this in perspective with the recent theoretical literature on optimal cost sharing. Ma and Riordan $(1997,2002)$ have highlighted the role played by income effects at determining the first-best level of health care use. ${ }^{28}$ I think this explains, at least partially, the difference in cost-sharing values that we find between the specifications with and without income effects. Table 8 shows the first-best thresholds, $O(c)$, for both specifications. ${ }^{29}$ From the results

${ }^{28}$ Unlike the no-income-effects model, the income-effects model "requires the consumer to be responsible for only a fraction of the treatment cost because his marginal valuation of income rises once a deductible is paid out of his income" (Ma and Riordan, 1997, p. 9). This means that if income effects are present, health care use is larger in the first best than in the absence of insurance, while both coincide when income effects are absent. See De Meza (1983) for a similar observation.

${ }^{29}$ It is easy to obtain $O(c)$ in the specification without income effects because $O(c)$ does not depend on either income or premium; see Ma and Riordan (2002) when $a=1$ and $b=0$. In my case, $O(c)=c^{1 / \gamma}$. I use $\gamma=1.58$ and $\sigma_{\varepsilon}=39.996$, which are the values estimated under the no-income-effects specification. These parameters are for costs valued in 2002 dollars. 


\begin{tabular}{ccc} 
TABLE 8 & \multicolumn{2}{c}{ First-Best Values $\left(\boldsymbol{O}(\boldsymbol{c}) / \boldsymbol{\sigma}_{\boldsymbol{\varepsilon} s}\right)$} \\
\hline Costs $(c)$ & Income Effects & No Income Effects \\
\hline 40 & .252 & .258 \\
80 & .302 & .400 \\
120 & .350 & .517 \\
200 & .441 & .715 \\
400 & .634 & 1.109 \\
600 & .783 & 1.433 \\
\hline
\end{tabular}

Note: Costs are valued in 2002 dollars.

in Tables 7 and 8, I conclude that both the difference in the first-best thresholds and the difference in cost-sharing values between the income-effects and no-income-effects specifications are positively related to the magnitude of the realized cost of treatment. Both specifications give similar results for episodes when costs are a small fraction of income, but they differ when costs are a large fraction of income.

\section{Conclusions}

- Unlike previous empirical research, I have used the principal-agent paradigm to estimate the optimal insurance contract for reimbursement health care insurance. Consequently, the optimal contract is derived from first principles and is robust to the presence of income effects. The empirical implementation allows me to estimate a new measure of moral hazard based on the correlation between unobservables influencing contractible and noncontractible variables. This new measure is complementary to the elasticity measure commonly used in the literature. I have also disentangled the treatment decision from the cost of treatment following previous research that attributed to the consumer the decision whether or not to seek treatment, while the cost decision is mostly left to the doctor.

The panel data used come from the RAND Health Insurance Experiment, a social experiment conducted between 1975 and 1982 in six different U.S. sites. Families participating in the experiment were randomly assigned to insurance plans, which allows one to consider the insurance status as exogenous. Structural parameters were estimated by simulated maximum likelihood using Monte Carlo integration to accommodate both sample selection (costs of treatment are observed only for those who decided to seek medical treatment) and individual unobserved heterogeneity.

The real data in frequencies of treatment and costs lie within the confidence interval predictions of my model. The real data exhibit a nonlinear effect of copayment on frequencies of treatment that my model does accommodate. I estimate a moderately high correlation (.79) between unobservables influencing health penalty and those influencing costs, which reduces the extent of moral hazard. This amounts to saying that about one-third of the residual health penalty variance remains unexplained by costs. The optimal out-of-pocket function shows a concave profile on costs, providing a larger coverage for episodes with larger costs. A piecewise linear contract provides an out-of-pocket function close to the optimal one. I estimate that the welfare loss due to moral hazard is $4.82 \%$ of the second-best total health care expenditure. A few remarks are important. My results apply only to acute illness episodes that do not require hospitalization. Given my limited information, the cost-sharing values for expensive treatments should be treated carefully. In particular, my results cannot be applied to catastrophic events. My sample is restricted to adults younger than 65 years old.

Due to lack of data, I have not considered the optimal mix of consumer and provider incentives (Ellis and McGuire, 1993). Consequently, I have looked for the optimal insurance contract restricted to the set of those that give incentives only to the consumer. My model seems to provide a hint on how a joint analysis of consumer and provider incentives could be carried out. Provider incentives could influence my cost function, should the necessary data be available. 
I would like to point out that this article has followed the tradition of a sovereign consumer who is able to correctly evaluate health status and, in particular for my model, health penalty. More research is needed to evaluate this point and its consequences. I have not studied multiple illness spells, so it is not clear how to extend my results for a period in which the individual could possibly face multiple illness episodes. Given the lack of data, I have not been able to incorporate uninsurable costs (such as travel costs and others) in consumer behavior. Overall, the article has provided an empirical analysis in the field of moral hazard in health care utilization in a fashion close to the principal-agent paradigm, though it is clear that substantial work is still needed.

\section{Appendix}

- The computation of the log-likelihood function follows.

The likelihood function contribution in (10) has two integrals, one over $s_{i t}$ and the other over $c_{i t}$. Since the loglikelihood function has two individual effects, then computation of the log-likelihood requires the evaluation of four integrals. Since evaluating integrals numerically is computationally intensive, there is an interest in cutting the number of integrals to compute. This can be done by taking advantage of the joint normality of $\left(\varepsilon_{s t}, \varepsilon_{c t}\right)$, since their conditional densities will also be normal and hence its cumulative distribution function (CDF) is available in standard econometric software.

Let $\tilde{\varepsilon}_{c t}\left(\varepsilon_{s t}\right)$ be the function that for each $\varepsilon_{s t}$ gives the value of $\varepsilon_{c t}$ such that the individual is indifferent between having or not having treatment. Let $g_{\varepsilon_{s t}}\left(\varepsilon_{s t}\right)$ be the normal density with zero mean and variance $\sigma_{\varepsilon s}^{2}$. Hence the second term of (10) can be obtained as

$$
\int_{-X_{s t} \beta_{s}-\mu_{s}}^{\infty} \operatorname{Pr}\left(\varepsilon_{c t}>\tilde{\varepsilon}_{c t}\left(\varepsilon_{s t}\right) \mid \varepsilon_{s t}\right) g\left(\varepsilon_{s t}\right) d \varepsilon_{s t},
$$

that is, in the range for $\varepsilon_{s t}$ for which the individual is ill: $\left(-X_{s t} \beta_{s}-\mu_{s},+\infty\right)$, the average probability of obtaining a draw from $\varepsilon_{c t}$ such that it is not worthwhile to have treatment $\left(\varepsilon_{c t}>\tilde{\varepsilon}_{c t}\left(\varepsilon_{s t}\right)\right)$. This expression can be approximated, using Monte Carlo integration, by

$$
\frac{1}{H} \sum_{r=1}^{H} \operatorname{Pr}\left(\varepsilon_{c t}>\tilde{\varepsilon}_{c t}\left(\hat{\varepsilon}_{s t}^{r}\right) \mid \hat{\varepsilon}_{s t}^{r}\right) * \Phi\left(\frac{X_{s t} \beta_{s}+\mu_{s}}{\sigma_{\varepsilon s}}\right),
$$

where $\hat{\varepsilon}_{s t}^{r}$ are random draws from $g\left(\varepsilon_{s t} \mid \varepsilon_{s t}>-X_{s t} \beta_{s}-\mu_{s}\right)$, the factor $\Phi\left(X_{s t} \beta_{s}+\mu_{s} / \sigma_{\varepsilon s}\right)$ corrects for this condition, and $H$ is the number of draws. Notice that the term $\operatorname{Pr}(\cdot)$ can be directly obtained by using the CDF of the normal. To obtain draws from $g\left(\varepsilon_{s t} \mid \varepsilon_{s t}>-X_{s t} \beta_{s}-\mu_{s}\right)$, I use the transformation $\Phi^{-1}\left(\Phi\left(-X_{s t} \beta_{s} / \sigma_{\varepsilon s}\right) u+(1-u)\right)$, where $u$ are random draws from the uniform $(0,1)$ distribution. Consequently, it is only necessary to compute one integral when computing the second term of (10).

Computation of (9) is performed in a similar way. $T_{t}$ equals 1 when $s_{t}>\tilde{s}\left(c_{t}\right)$, that is, $\varepsilon_{s t}>\tilde{s}\left(c_{t}\right)-X_{s t} \beta_{s}-\mu_{s}$. Hence the probability of $T_{t}=1$ and observing costs $c_{t}$ is

$$
\int_{\tilde{s}\left(c_{t}\right)-X_{s t} \beta_{s}-\mu_{s}}^{+\infty} h_{\varepsilon c \mid \varepsilon s}\left(\tilde{\varepsilon}_{c}\left(\varepsilon_{s t}\right)\right) g\left(\varepsilon_{s t}\right) d \varepsilon_{s t},
$$

where $\tilde{\varepsilon_{c}}\left(\varepsilon_{s t}\right)=\ln \left(c_{t}\right)-\alpha \ln \left(1+X_{s t} \beta_{s}+\mu_{s}+\varepsilon_{s t}\right)-X_{c t} \beta_{c}-\mu_{c}$ is the value of $\varepsilon_{c t}$ that gives $c_{t}$ conditional on $\varepsilon_{s t}$. Notice that $\varepsilon_{c t} \mid \varepsilon_{s t}$ follows a normal distribution and $h_{\varepsilon c \mid \varepsilon s}$ is its density. In the same fashion as before, the above integral can be computed, using Monte Carlo integration, as

$$
\frac{1}{H} \sum_{r=1}^{H} h_{\varepsilon c \mid \varepsilon s}\left(\tilde{\varepsilon}_{c}\left(\hat{\varepsilon}_{s t}^{r}\right)\right) *\left[1-\Phi\left(\frac{\tilde{s}\left(c_{t}\right)-X_{s t} \beta_{s}-\mu_{s}}{\sigma_{\varepsilon s}}\right)\right]
$$

where $\hat{\varepsilon}_{s t}^{r}$ are random draws from $g\left(\varepsilon_{s t} \mid \varepsilon_{s t}>\tilde{s}\left(c_{t}\right)-X_{s t} \beta_{s}-\mu_{s}\right)$, and the last factor corrects for this condition. For the sake of exposition, I have omitted both the $i$ subindex and the conditionality on $\left(\mu_{s}, \mu_{c}\right)$. The above expressions are used to compute $L_{0 i t}$ and $L_{1 i t}$ in (10) and (9). Finally, computation of (11) is also done through Monte Carlo integration by drawing $H$ pairs of $\left(\hat{\mu}_{s}^{r}, \hat{\mu}_{c}^{r}\right)$ from the corresponding bivariate normal distribution, that is,

$$
\ln L=\sum_{i=1}^{N} \ln \left(\frac{1}{H} \sum_{r=1}^{H} \prod_{t=1}^{q_{i}} L_{i t}\left(\hat{\mu}_{s}^{r}, \hat{\mu}_{c}^{r}\right)\right)
$$


The above simulation routine gives a log-likelihood that is smooth in the parameters that allow one to use standard gradient methods for maximization of the log-likelihood, as well as to obtain standard errors using standard inference procedures. This estimator, as any computed through simulated maximum likelihood, is consistent when the number of draws tends to infinity. I have used $H=40$ with antithetics as a bias-reduction technique. To assess the reliability of my simulation routine, I estimated a single-period model without time-invariant unobserved heterogeneity using both my routine and using numerical integration by quadrature methods (Judd, 1998) directly in (10) and (9). I found very similar results in both coefficients and standard errors. The results of this comparison are available from the author upon request.

\section{References}

Arrow, K.J. "Uncertainty and the Welfare Economics of Medical Care.” American Economic Review, Vol. 53 (1963), pp. 941-973.

BesLey, T.J. "Optimal Reimbursement Health Insurance and the Theory of Ramsey Taxation." Journal of Health Economics, Vol. 7 (1988), pp. 321-336.

Biais, B., Bisière, C., AND DÉCAMPS, J.P. "A Structural Econometric Investigation of the Agency Theory of Financial Structure.” Mimeo, GREMAQ-IDEI, 1999.

Blomevist, A.G. “Optimal Non-linear Health Insurance.” Journal of Health Economics, Vol. 16 (1997), pp. $303-321$.

_Does the Economics of Moral Hazard Need to be Revisited? A Comment on the Paper by John Nyman." Journal of Health Economics, Vol. 20 (2001a), pp. 283-288.

—. "The Economics of Moral Hazard Revisited: Rejoinder." Journal of Health Economics, Vol. 20 (2001b), p. 299.

Buchanan, J.L., Keeler, E.B., Rolph, J.E., and Holmer, M.R. "Simulating Health Expenditures Under Alternative Insurance Plans.” Management Science, Vol. 37 (1991), pp. 1067-1090.

Cardon, J.H. ANd Hendel, I. "Asymmetric Information in Health Insurance: Evidence from the National Medical Expenditure Survey." RAND Journal of Economics, Vol. 32 (2001), pp. 408-427.

ChiAproRI, P.-A. "Econometric Models of Insurance Under Asymmetric Information.” In G. Dionne, ed., Handbook of Insurance. Boston: Kluwer Academic, 2000.

- And Salanié, B. “Testing Contract Theory: A Survey of Some Recent Work.” In M. Dewatripont, L.P. Hansen, and S.J. Turnovsky, eds., Advances in Economics and Econometrics-Theory and Applications, Eighth World Congress. New York: Cambridge University Press, 2003.

Cutler, D.M. "Health Care and the Public Sector." In A.J. Auerbach and M. Feldstein, eds., Handbook of Public Economics, Vol. 4. Amsterdam: North-Holland, 2002.

- AND Zeckhauser, R. “The Anatomy of Health Insurance.” In A.J. Culyer and J.P. Newhouse, eds., Handbook of Health Economics, Vol. 1A. Amsterdam: North-Holland, 2000.

DE MezA, D. "Health Insurance and the Demand for Medical Care." Journal of Health Economics, Vol. 2 (1983), pp. 47-54.

Ellis, R.P. "Rational Behavior in the Presence of Coverage Ceilings and Deductibles." RAND Journal of Economics, Vol. 17 (1986), pp. 158-175.

- And McGuire, T.G. "Supply-Side and Demand-Side Cost-Sharing in Health Care." Journal of Economic Perspectives, Vol. 7 (1993), pp. 135-151.

Feldman, R. AND Dowd, B. “A New Estimate of the Welfare Loss of Excess Health Insurance." American Economic Review, Vol. 81 (1991), pp. 297-302.

Feldstein, M.S. “The Welfare Loss of Excess Health Insurance.” Journal of Political Economy, Vol. 81 (1973), pp. 251-280.

Ferrall, C. and Shearer, B. "Incentives and Transactions Costs Within the Firm: Estimating an Agency Model Using Payroll Records.” Review of Economic Studies, Vol. 66 (1999), pp. 309-338.

Goffe, W.L., Ferrier, G.D., And Rogers, J. "Global Optimization of Statistical Functions with Simulated Annealing." Journal of Econometrics, Vol. 60 (1994), pp. 65-99.

Gilleskie, D.B. “A Dynamic Stochastic Model of Medical Care Use and Work Absence.” Econometrica, Vol. 66 (1998), pp. $1-45$.

Haubrich J.G. "Risk Aversion, Performance Pay and the Principal-Agent Problem.” Journal of Political Economy, Vol. 102 (1994), pp. 258-276.

Heckman, J.J. “Sample Selection Bias as a Specification Error.” Econometrica, Vol. 47 (1979), pp. 153-161.

JuDD, K.L. Numerical Methods in Economics. Cambridge, Mass.: MIT Press, 1998.

Keeler, E.B. And RolPh, J.E. “The Demand for Episodes of Treatment in the Health Insurance Experiment.” Journal of Health Economics, Vol. 7 (1988), pp. 337-367.

- Newhouse, J.P., And Phelps, C.E. "Deductibles and the Demand for Medical Care Services: The Theory of a Consumer Facing a Variable Price Schedule Under Uncertainty.” Econometrica, Vol. 45 (1977), pp. 641-656.

Laffont, J.-J. And Tirole, J. A Theory of Incentives in Procurement and Regulation. Cambridge, Mass.: MIT Press, 1993.

Ma, C.-T.A. And Riordan, M.H. "Health Insurance, Moral Hazard and Managed Care.” Boston University Industry Studies Program Working Paper no. 80, 1997.

AND - "Health Insurance, Moral Hazard and Managed Care." Journal of Economics and Managment Strategy, Vol. 11 (2002), pp. 81-107.

(c) RAND 2003 
MACE, B.J. "Full Insurance in the Presence of Aggregate Uncertainty." Journal of Political Economy, Vol. 99 (1991), pp. 928-956.

Macho-Stadler, I. and Pérez-Castrillo, J.D. An Introduction to the Economics of Information: Incentives and Contracts, 2d ed. New York: Oxford University Press, 2001.

Manning, W.G. AND Marquis, M.S. "Health Insurance: The Tradeoff Between Risk Pooling and Moral Hazard.” Journal of Health Economics, Vol. 15 (1996), pp. 609-639.

AND — . "Health Insurance: Tradeoffs Revisited." Journal of Health Economics, Vol. 20 (2001), pp. $289-293$.

, Newhouse, J.P., Duan, N., Keeler, E.B., Leibowitz, A., And Marquis, M.S. "Health Insurance and the Demand for Medical Care: Evidence from a Randomized Experiment." American Economic Review, Vol. 77 (1987), pp. 251-277.

Margiotta, M.M. And Miller, R.A. "Managerial Compensation and the Cost of Moral Hazard.” International Economic Review, Vol. 41 (2000), pp. 669-719.

Marquis, M.S. and Holmer, M.R. "Alternative Models of Choice Under Uncertainty and the Demand for Health Insurance." Review of Economics and Statistics, Vol. 78 (1996), pp. 421-427.

Newhouse, J.P. AND The Insurance EXPERIMENT Group. Free for All? Lessons from the RAND Health Insurance Experiment. Cambridge, Mass.: Harvard University Press, 1993.

NYMAN, J.A. "The Income Transfer Effect, the Access Value of Insurance and the RAND Health Insurance Experiment." Journal of Health Economics, Vol. 20 (2001), pp. 295-298.

PaArsch, H.J. and Shearer, B. "Piece Rates, Fixed Wages, and Incentive Effects: Statistical Evidence from Payroll Records.” International Economic Review, Vol. 41 (2000), pp. 59-92.

Pauly, M.V. "The Economics of Moral Hazard. Comment." The American Economic Review, Vol. 58 (1968), pp. 531537.

Salanié, B. The Economics of Contracts: A Primer. Cambridge, Mass.: MIT Press, 1997.

Townsend, R.M. "Risk and Insurance in Village India.” Econometrica, Vol. 62 (1994), pp. 539-591.

Winter, R.A. “Optimal Insurance Under Moral Hazard.” In G. Dionne, ed., Handbook of Insurance. Boston: Kluwer Academic, 2000.

ZecKHAuSER, R. "Medical Insurance: A Case Study of the Tradeoff Between Risk Spreading and Appropiate Incentives." Journal of Economic Theory, Vol. 2 (1970), pp. 10-26. 